\title{
NSR and NSTC projects: environmental and economic efficiency assessment of the goods' overseas transportation
}

\author{
Sergey Nikonorov, Alexander Krivichev*, Vladimir Sidorenko \\ M.V. Lomonosov Moscow State University, Leninskie Gory, GSP-1, Moscow, 119991, Russia
}

\begin{abstract}
The authors attempt to assess the environmental and economic efficiency of investment projects for the goods transportation by the northern seas of Russia taking into account the relevance of the topic of cargo transportation by means of the "Northern Sea Route" (NSR) and new concept of the digital format of the "Northern Sea Transit Corridor" (NSTC) implemented by the "Rosatom" State Corporation. The structure of import-export and transit traffic by the NSR in 2020 is considered. The goal of the article is to evaluate the efficiency of investment project for the goods transportation forwards and backwards by the NSR from Murmansk city to PetropavlovskKamchatsky city using the example of the "Andrey Osipov" shipping facility. Some indicators were assessed: planned revenue, payback period; NPV, environmental damage. The following results are obtained: the payback period is 10 years; by using the naval fuel oil over a ten-year period, 1101.6 tons of $\mathrm{SO}_{\mathrm{x}}, 143.1$ tons of $\mathrm{CO}_{2}, 288.9$ tons of $\mathrm{NO}_{\mathrm{x}}$ will be emitted. In addition, the authors propose an innovative approach to creation of ships from new materials and technologies based on the modern paradigm of "Accelerated Digital Certification".
\end{abstract}

\section{Introduction}

The Arctic is a unique ecosystem with an amazing fauna, a reserve source of drinking water and huge reserves of minerals. The polar possessions of Russia make up 18\% of the entire territory of the Russian Federation, where less than $2 \%$ of the population of Russia lives. The Arctic produces $10 \%$ of the world's oil and $25 \%$ of natural gas, while $80 \%$ of all Arctic oil and gas is concentrated in the Russian part.

The sustainable development of the Arctic territories of Russia is one of the priority areas for the development of the Russian economy $[1,2,3]$.

\section{NSR, NSTC, SSR logistics}

According to the Decree of the Russian President dated May 7, No. 204, 2018, the Federal project "Northern Sea Route" (2018-2024) and the "Infrastructure Development Plan" of the "Northern Sea Route" (NSR) until 2035 (borders of the NSR determined by international law from Novaya Zemlya to Chukotka) are established (Fig. $1)$.

According to the documents, the main tasks for the NSR development are: increasing the freight traffic by the NSR up to 80 million tons per year up to 2024 and up to 120 million tons per year up to 2030; navigation and hydrographic support of navigation on the NSR; ensuring year-round navigation of ships on the NSR; creation and reconstruction of transport and port infrastructure; construction of the fleet. The ports will be involved: Arkhangelsk, Murmansk, Sabetta, Dikson, Dudinka, Pevek, Khatanga, Petropavlovsk-Kamchatsky. The implementation of the tasks set within the Federal project of NSR is carried out at the expense of the federal budget.

"Northern Sea Route" is the shortest sea route between the European part of Russia and the Far East. The Russian legislation defined it as "the historically established national unified transport communication of Russia in the Arctic".

The use of cargo transportation by the NSR, in addition to reducing the travel time from 33 to 20 days, provides a number of other advantages:

- Saving on fuel almost 2 times compared to the southern sea route.

- No need to pay for the passage of the vessel (unlike the Suez Canal).

- No queues (as is the case with the Suez Canal).

- There is no risk of attack by pirates.

Import-export traffic by the NSR in 2020 was carried out mainly by river-sea ships, without class, Ice2, Arc4, Arc5, Arc7, and most of the traffic was performed by the Arc7 class of ships.

*Corresponding author: krivichev@live.ru 

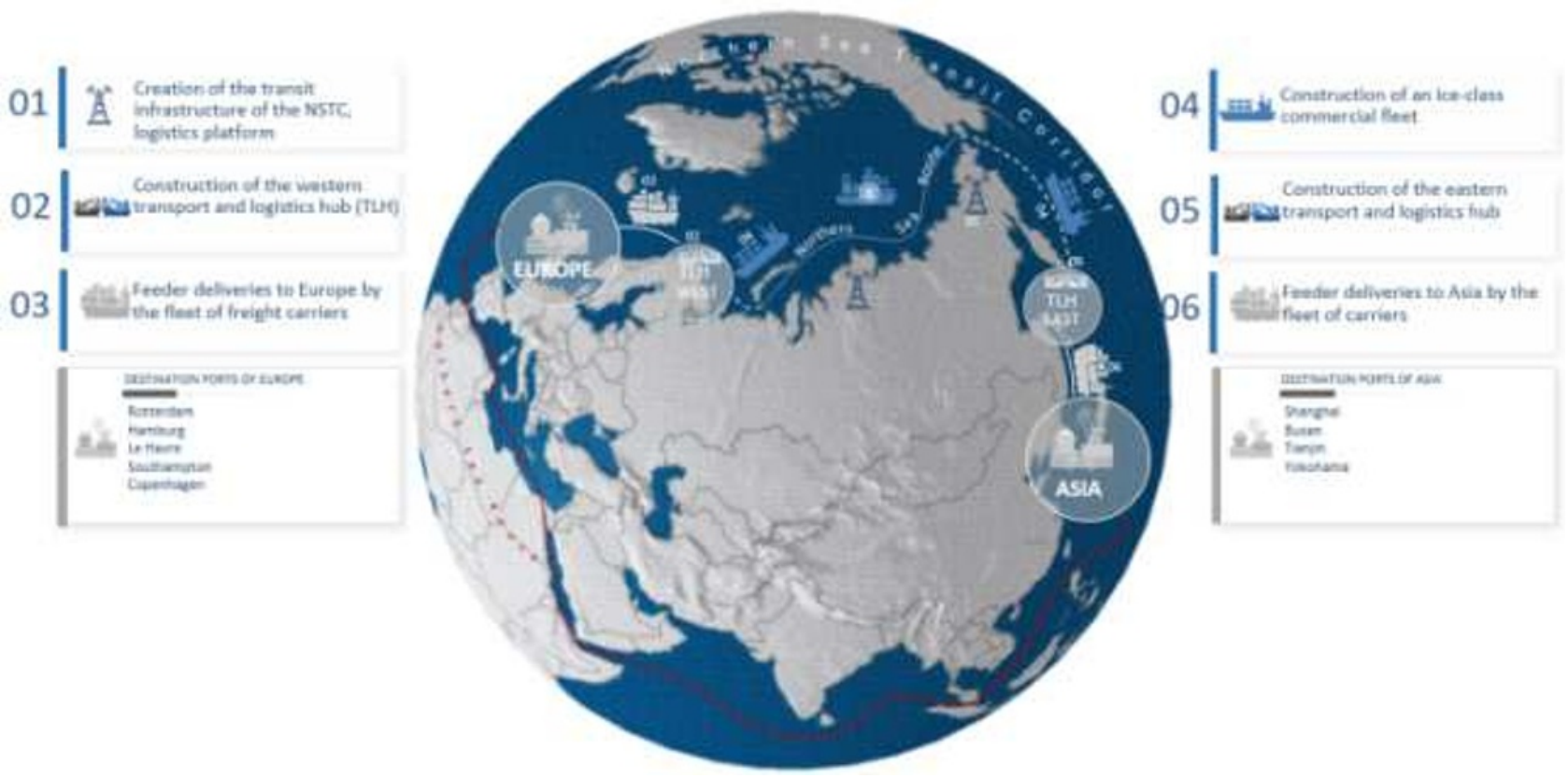

Figure 1. The logistic of the "Northern Sea Route" (NSR), "Northern Sea Transit Corridor" (NSTC), "Southern Sea Route" (SSR)

The structure of import-export traffic (Fig. 2) in 2020 was as follows: LNG - 59\%; oil - 24\%; general cargo $11 \%$; gas condensate (NGL) - 3\%; oil products - $2 \%$; coal $-1 \%$; ore concentrate $(\mathrm{Au})-0.2 \%$. Moreover, 3.2 million tons of cargo were transported.

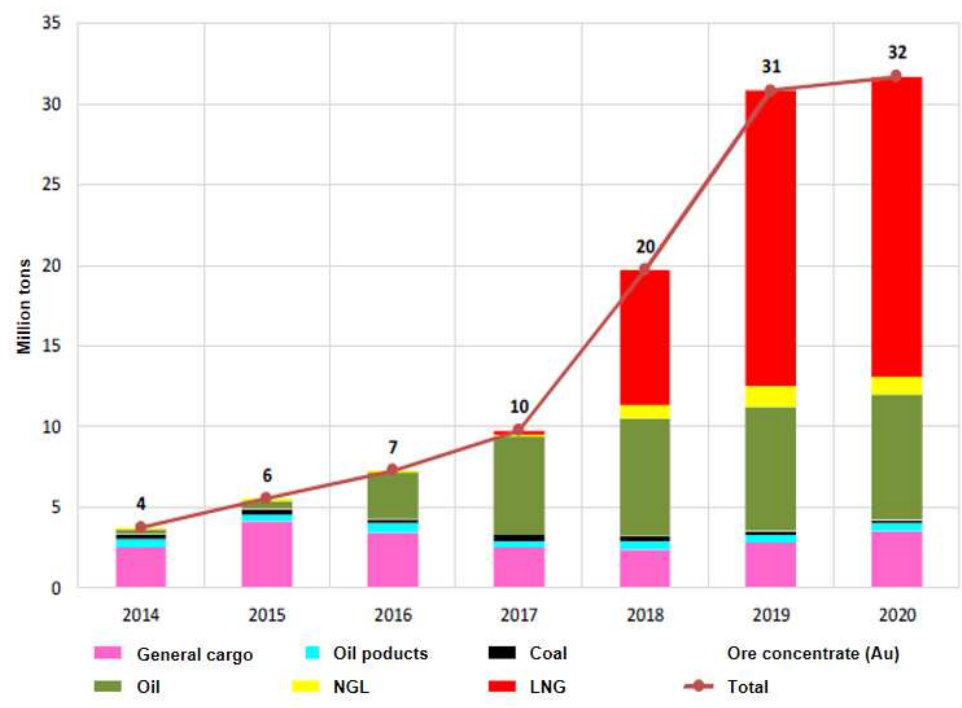

Figure 2. The structure of import-export traffic by NSR / NSTC

LNG exports from Russia have shown good results in recent years. Even in Europe, as stated in the report of the International Association of Liquefied Gas Importers, Moscow bypasses Washington in terms of LNG supplies (in $2018-4.4$ million tons versus 2.7 million tons, in 2019 - 15.07 million tons versus 12.72 million tons).

Transit transportation by the NSR in 2020 was carried out, among other things, by ships of four ice classes: Ice1, Ice2, Arc4, Arc5, and more than 800 thousand tons of cargo were transported.

In 2020, transit traffic by the NSR in the structural section of freight traffic was as follows: iron ore $-78 \%$; general cargo $-7 \%$; cellulose $-5 \%$; mineral fertilizers -
$5 \%$; bulk cargo - 2\%; equipment - $2 \%$; petroleum products $-1 \%$; frozen fish $-0.5 \%$. Moreover, more than 1 million tons of iron ore were transported, and the rest of the transported goods accounted for about 250 thousand tons.

To develop the transit potential and geographic advantages of the NSR, the "Rosatom" State Corporation in 2019 initiated a project to develop the logistics system of the "Northern Sea Transit Corridor" (NSTC). The concept of the project was developed within the framework of a strategic program for the creation of an international operator-logistics services.

The project includes: 
- creation of the transit infrastructure of the NSTC and a logistic platform,

- construction of a western transport and logistic hub,

- feeder deliveries to Europe by the fleet of cargo carriers,

- construction of a commercial ice class fleet (30 units),

- construction of the eastern transport and logistics hub,

- feeder deliveries to Asia by the fleet of cargo carriers.

The core of the project is the creation of a commercial fleet with a design service life of the vessel of at least 40 years. The potential of the project is 4.5 million TEU per year (A twenty-foot equivalent unit (TEU or teu from English twenty-foot equivalent unit) is a conventional unit for measuring the capacity of freight vehicles. It is often used when describing the capacity of container ships and container terminals).

The Far East Development Fund, together with VEB.RF, the Ministry for the Development of the Russian Far East and the M.V. Lomonosov Moscow State University, are developing a digital platform Arctic Labs, which will be based on the digital twin of the "Northern Sea Route" (CD NSR): a dynamic mathematical model that will allow developing scenarios development of both the Arctic as a whole and its individual territories. With the help of the NSR CS platform, it will be possible to develop logistics routes, taking into account in real time more than 10 thousand parameters: Arctic resources, infrastructure, transport, shipbuilding, transportation options, economy, ecology, etc. This will allow a comprehensive assessment of: the feasibility of investment and infrastructure projects, the impact of projects on the dynamics of development of regions and individual territories, the impact of the Arctic economy on the GDP of the Russian Federation.

The authors assessed the efficiency of the investment project for the transportation of goods by the NSR from Murmansk to Petropavlovsk-Kamchatsky and vice versa, using the example of a shipping facility - "Andrey Osipov" (hereinafter referred to as the Arc5 class vessel). The goal was to transport cargo in containers from the port of Murmansk to the port of PetropavlovskKamchatsky and back, taking into account downtime, calculating revenue, net present value, payback period and environmental damage.

In connection with this goal, the following tasks were solved: the container capacity of the ship, the volume of heavy fuel oil tanks, the ship's speed per hour, and the number of flights were determined. In addition, the calculation of the total investment costs for the project has been made. At the same time, the salary of the crew and services when renting containers were taken into account:

- forwarding to the port of departure,

- acceptance of cargo at the port,

- temporary storage on board,

- mount and fastening material,

- sea freight,

- icebreaking dues,

- unloading from the ship,

- temporary storage in the port,

- intraport movements.

\section{Results}

As a result of a study to assess the effectiveness of an investment project, the following results were obtained:

- the payback period of the project was 10 years, and the average amount per year for business development was 14 million rubles;

- with naval fuel oil using over a ten-year period the 1101.6 tons of sulfur oxides, 143.1 tons of CO2, 288.9 tons of nitrogen oxides will be emitted.

If we consider the simultaneous operation of a pool of ships of this type on the NSR, then the ecological footprint will be multiplied.

This is relevant, since the volume of emissions from ships of the world Merchant fleet is about $3 \%$ of greenhouse gas emissions in the world, since these ships operate on heavy fuel oil. It is known that the concentration of sulfur in heavy fuel oil is 1800 times higher than in diesel fuel for cars. Therefore, an ecological and economic assessment of the efficiency of the work of vessels of various classes is necessary.

At the same time, applying an innovative approach to creating a ship from new materials and technologies based on the modern paradigm of "Accelerated Digital Certification", it is possible to significantly increase the efficiency of using ships of a new generation. The use of carbon fiber materials in the process of creating a ship for NSTC can give the following advantages: reduction of the ship's weight by 30-40\%; the possibility of building on the slipway. A decrease in the mass of the ship's hull will lead to an increase in the specific power of the gas-power plant (GPP) by $30 \%$, as well as to a decrease in the draft to $10-12 \mathrm{~m}$, which will allow the ship to pass through all the "depths" of the NSR. And the use of CFRP shipping containers, in addition to reducing weight, will increase the container service life from 5 to 30 years and reduce painting costs. The use of the power plant will many times reduce the ecological footprint and increase the ecological and economic characteristics of the pool of ships carrying cargo in the water area of the NSR.

In terms of environmental impact, ships with a nuclear power plant (NPP) have zero $\mathrm{CO}_{2}$ emissions [2]. That is, it is a $100 \%$ ship with no carbon footprint. The use of ships with nuclear power plants on the NSTC routes will make it possible to make a real one hundred percent "green mile".

In addition, digital modeling was chosen as a fundamental basis for the implementation of the NSTC project, which includes:

- model-oriented system engineering,

- simulation modeling (Anylogic etc.),

- digital technologies and platform solutions,

- design and use of digital twins (Fig. 3) and digital shadows on the CML-BenchTM platform at all stages of the ship's life cycle,

- other digital technologies. 


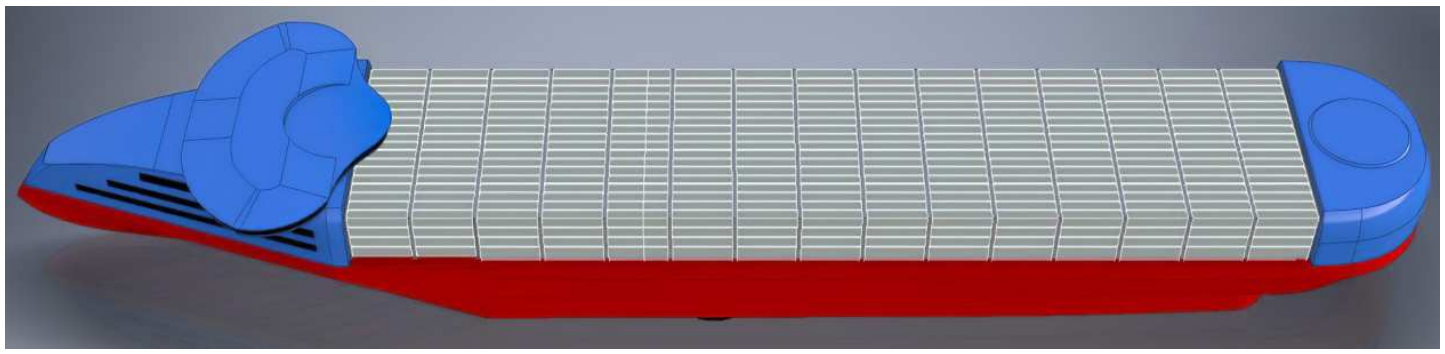

Figure 3. The example of digital twins for container ship "Ice Needle" (Marine Engineering Center, Moscow)

It is necessary to link the work on the creation of digital twins at various stages of the ship's life cycle, the use of information support systems, covering research, design, production, integrated logistics support, optimization of ship routes. This approach will create opportunities for more efficient use throughout the life cycle of ships for the carriage of goods by the NSR, as well as faster and more accurate economic calculations taking into account the environmental factor.

With global warming, the rate of ice melting in the Arctic has increased, and the importance of the Arctic strategy has become increasingly evident, which has caused competition among many countries. The Arctic Development Strategy 2035 is the first step towards sustainable development of the Arctic. To achieve a favorable situation in the Arctic, we need to formulate appropriate Arctic regional strategies in the Arctic Zone of the Russian Federation (AZRF) and in the Barents macro-region, so that Russia occupies an advantageous position in the future world order. Russia's 2021 chairmanship of the Arctic Council can partially ensure energy security and the security of sea transport channels, which is becoming a strategic direction for Russia's economic development. My country needs to assess the impact of the Arctic on the future international structure of the world and formulate an international Arctic strategy, with the involvement of 8 countries of the Arctic Council and with the involvement of observer countries (primarily China).

The opening of the Arctic waterway will change world trade and help create a super-Arctic economic circle dominated by Russia, North America and Northern Europe, which in turn will affect the economic and geopolitical structure of the entire world. If the new channel is opened, it will reduce the sea freight traffic, significantly reduce transport costs, save time and promote the development of foreign trade. The energy security of China, Korea, Japan and other countries, when importing and exporting goods, will be guaranteed. Russia's International Arctic Strategy can strengthen exchanges and cooperation with seven other Arctic countries, enhance its influence in the Arctic region and protect strategic interests. On the other hand, it attaches great importance to common interests with non-polar countries and strengthens exchanges and cooperation with non-polar countries such as China, Korea, Japan, India and Australia in Arctic affairs. By pursuing common interests, this will contribute to the internationalization of the management and development of the Arctic and will help guide the development of Arctic issues in a reasonable and fair direction.

\section{Conclusion}

Thus, the projects of the "Northern Sea Route" and the "Northern Sea Transit Corridor" are key vectors for the development of the Russian Arctic, and despite the fact that these projects are aimed at increasing the competitiveness of the Russian economy in the domestic and world markets, in solving the tasks set, they will allow the implementation of a number of other related projects (use of the best available technologies, research and protection of Arctic ecosystems, optimization of logistics solutions, use of digital twins and platforms, big data analysis $[5,6,7]$, etc.).

\section{References}

1. Vitaly Sergeev, et al. Transportation Research Procedia. 54. (2021).

2. Alexander I. Krivichev, Eugene G. Smirnov Management sciences in the modern world. 2 (2). (2016).

3. V.M. Gruzinov, et al. Arctic: Ecology and Economics 1, 33 (2019).

4. I. Petrov, et al. IOP Conference Series: Earth and Environmental Science 377, 1 (2019).

5. Eric Van Der Horn, Sankaran Mahadevan Decision Support Systems. 145 (2021).

6. Vladimir N. Sidorenko, Pavel M. Krivenkov Dynamic scenario modeling. Optimization of the logistics solutions. Calculation of the economics of complex systems at some levels of detail at all stages of the life cycle on the example of small NPP projects in the "Rosatom" State Corporation. About approaches to the creation of digital models in the project of the Northern Sea Transit Corridor formation. Digital ship as a 
basis of the transit infrastructure. "Rosatom" State Corporation, LLC "Rusatom Cargo", PJSC “Inteltech”, St. Petersburg, Russia (2019).

7. Sergey M. Nikonorov journal

Scientific Works of the Free Economic Society of Russia. 6, 226 (2020). 